\title{
Continuously Monitored Canopy Temperature as a Proxy for Plant Water Status
}

\author{
James R. Mahan ${ }^{1}$, Andrew W. Young ${ }^{2}$, Paxton Payton ${ }^{1}$ \\ ${ }^{1}$ Cropping Systems Research Laboratory, The Agricultural Research Service, United States Department of \\ Agriculture (USDA/ARS ${ }^{\#}$ ), Lubbock, TX, USA \\ ${ }^{2}$ Plant and Soil Science Department, Texas Tech University, Lubbock, TX, USA \\ Email: ${ }^{*}$ james.mahan@ars.usda.gov
}

Received 18 July 2015; accepted 8 September 2015; published 11 September 2015

Copyright (C) 2015 by authors and Scientific Research Publishing Inc.

This work is licensed under the Creative Commons Attribution International License (CC BY). http://creativecommons.org/licenses/by/4.0/

(c) (7) Open Access

\begin{abstract}
Water deficits are major limiters of crop yield worldwide. The detection of water deficits can be difficult. Measurements of the aerial and soil environment are often used to infer the water status and detect water deficits. Since crop yield accumulates incrementally and cumulatively over seasonal time scales, continuous direct monitoring of the water status of the crop may provide needed insight into plant/environment interactions. Canopy temperature can be measured near continuously on seasonal scales in the field. Cotton was grown under 11 irrigation regimes in 2009 and 2010 with water deficits from $26 \%$ to $86 \%$ of crop evapotranspiration. Yield varied accordingly from $\sim 500 \mathrm{~kg} \cdot \mathrm{ha}^{-1}$ to $\sim 2600 \mathrm{~kg} \cdot \mathrm{ha}^{-1}$. Canopy temperature was measured on a 15-minute interval for $\sim 65$ days in each year. Yield was described by a linear function of total water (irrigation + rain) for each year with similar slopes and different intercepts. When canopy temperature was used as a surrogate for total water, yield was linearly related to daytime leaf-to-air VPD, mean seasonal canopy temperature, mean seasonal daytime canopy temperature, and cumulative seasonal daytime canopy temperature. Limiting the analysis to daytime periods improved the ability to account for yield variation. Mean daytime seasonal canopy temperature and cumulative seasonal daytime temperature were most effective in accounting for yield variation across the seasons with a single regression line for both years.
\end{abstract}

\footnotetext{
${ }^{*}$ Corresponding author.

\#The US Department of Agriculture (USDA) prohibits discrimination in all its programs and activities on the basis of race, color, national origin, age disability, and where applicable, sex, marital status, familial status, parental status, religion, sexual orientation, genetic information, political beliefs, reprisal, or because all or part of an individual's income is derived from any public assistance program. (Not all prohibited bases apply to all programs.) Persons with disabilities who required alternative means for communication of program information (Braille, large print, audiotape, etc.) should contact USDA's TARGET Center at (202) 720-2600 (voice and TDD). To file a complaint of discrimination, write to USDA, Office of Civil Rights, 1400 Independence Avenue, S.W., Washington DC 20250-9410, or call (800) 795-3272 (voice) or (202) 720-6382 (TDD). USDA is an equal opportunity provider and employer.
}

How to cite this paper: Mahan, J.R., Young, A.W. and Payton, P. (2015) Continuously Monitored Canopy Temperature as a Proxy for Plant Water Status. American Journal of Plant Sciences, 6, 2287-2302.

http://dx.doi.org/10.4236/ajps.2015.614232 
Keywords

Canopy Temperature, Cotton, Drip Irrigation, Evapotranspiration, Gossypium hirsutum, Yield

\section{Introduction}

Projected world population growth, a declining base of agricultural land and diminished water resources are creating a need for germplasm and management practices that are more sustainable in terms of the the conversion of water into yield. In the past, agricultural water management has focused on the timely application of water to prevent water deficits. In the future, water deficits will become more common and the focus will change to the identification, quantification and management of water deficits.

Water deficits in crops vary over diurnal and seasonal timescales within continuously variable environments. Water deficits typically arise and are alleviated in a cyclic manner over days and weeks within a growing season with crops experiencing water deficits of varying intensity and duration at virtually all developmental stages. New tools to improve monitoring of the magnitude and intensity of water deficits on seasonal timeframes in the field might improve stress management options.

Variation in environmental conditions, rain, and irrigation over seasonal time scales makes it difficult to define water deficits and their effects on crop performance in the field. Sap flow gauges and leaf turgor sensors are capable of directly measuring crop water use [1]-[3], though the utility of such measuring devices is often limited by their cost and complexity.

In the absence of direct measurement of crop water use, it is often inferred from measurements of the environment, irrigation, rain and soil moisture [4]. A water balance approach for estimating crop water use requires a means of determining the amount of water that enters the soil and the fraction of that amount that passes through the plant as transpiration over time. Direct measurement of soil moisture using soil probes or soil samples is relatively straightforward by a variety of means though the spatial and temporal resloution is often limiting [5]-[7]. Thus, even when the amount of water in the soil is well characterized, the question of how much is actually available to the crop at any moment in time remains.

Two research topics are relevant at this point; 1 ) detailed descriptions of plant performance in the field under production relevant conditions (seasonal phenotypes) and 2) an ability to compare the physiological responses of plants to management and environmental variation under field conditions.

The canopy temperature of plants has been used in the detection plant water deficits for decades [8]-[11]. The development of a simplified infrared thermometry (IRT) system [12] [13] provides a tool for monitoring canopy temperature on a near-continuous time scale over the course of a growing season.

The goal of this study was to investigate the utility of near-continous seasonal monitoring of canopy temperature as a tool for detecting differences in crop water use. Continuous canopy temperature, crop evapotranspiration, and other environmental parameters were measured or calculated along with yield for cotton grown over a range of irrigation treatments for two consecutive seasons. The relationships among yield, water applied, water use, and canopy temperature were determined and are presented here with a discussion regarding the value of continuous monitoring of canopy temperature.

\section{Materials and Methods}

\subsection{Location and Cultural Practices}

The study was carried out on the Texas Tech University Research farm in Lubbock, TX in 2009 and 2010. The research farm is at N33.60203 W101.73003 at an elevation of $992 \mathrm{~m}$. The soil was an Acuff sandy clay loam soil (Fine-loamy, mixed, superactive, thermic Aridic Paleustolls) (USDA-NRCS 2010). Plots consisted of four 10 m-rows planted east to west on a $1 \mathrm{~m}$ row spacing that were irrigated by a sub-surface drip irrigation system with irrigation tape placed approximately $0.20 \mathrm{~m}$ below each row. Cotton (variety DP147RF) was planted on day of year (DOY) 135 in 2009 and on DOY 140 in 2010 at 12.8 seeds $\mathrm{m}^{-1}$. DP147RF is a Roundup Ready Flex variety with good fiber quality and yield potential. The plots were harvested on DOY 294 in 2009 and on DOY 301 in 2010. The center two rows of each plot were harvested using a modified John Deere 7455 stripper 
equipped with load cells. The cotton from the two rows was weighed and then a grab sample for ginning and fiber quality analysis was taken. Ginning was completed on a twenty-saw gin stand, after being processed by a lint cleaner. Yield plots were not replicated and a single value is reported for each treatment.

\subsection{Irrigation}

Thirteen target irrigation treatments, that ranged from 0 to $6 \mathrm{~mm}$ in $0.5 \mathrm{~mm}$ increments, were applied through SDI in both the 2009 and 2010. The treatment targets ranged from 0 to $6 \mathrm{~mm}$ in $0.5 \mathrm{~mm}$ increments and were designed to cover a range from rainfed to full irrigation for the location. Irrigation was applied on a daily basis, for 76 days (DOY 188 to DOY 264) in 2009 and for 41 days (DOY 215 to DOY 256) in 2010. Thirteen zones were randomly assigned for each year. The irrigation treatments were not replicated.

\subsection{Temperature and Relative Humidity}

Canopy temperature in each irrigation treatment was monitored with a single infrared thermometer (Smartcrop ${ }^{\mathrm{TM}}$ Smartfiled Inc., Lubbock, TX, USA) that was placed approximately $20 \mathrm{~cm}$ above the canopy at an angle of approximately $60^{\circ}$ from vertical. The infrared thermometer (IRT) had a 1:1 view ratio which allowed approximately $20 \mathrm{~cm}$ of plant canopy to be monitored. The height of the IRTs above the canopy was adjusted to maintain the $20 \mathrm{~cm}$ canopy diameter as the crop grew. Each IRT measured the plant canopy at a one-minute interval with an average of these readings calculated every fifteen minutes. The calculated 15-minute averages were relayed to a base station. This resulted in 96 data points per day that were compiled and catalogued for subsequent analysis. There was a sincel IRT in each treatment with no replications. Air temperature and relative humidity (sensor type )were measured at $2 \mathrm{~m}$ above the ground at the edge of the plots on the same interval as the IRT sensors.

A canopy period that covers the interval when the plant canopy was of sufficient size for canopy temperature to be monitored was defined in each year. The canopy period began 67 days after planting (DAP) in 2009 and ranged from DOY 202 to DOY 268 (66 days) and was similar in 2010, beginning at 66 DAP and ranging from DOY 205 to DOY 269 (64 days). Canopy temperature was monitored over this interval and all analysis involving canopy temperature are made within this period.

\subsection{Vapor Pressure Deficit Calculation}

The vapor pressure deficit (VPD) of the air for each season was calculated using the simplified Murray equation [14]. The equation used for calculating saturation vapor pressure $\left(e_{s}\right)$ is:

$$
e_{s}=0.6108 \exp (17.27 T / 237.3+T) \text { where } T=\text { air temperature }\left({ }^{\circ} \mathrm{C}\right) \text {. }
$$

The vapor pressure of the atmosphere was calculated from the relative humidity $(R H)$ measurements by the formula,

$$
e_{a}=(R H / 100) e_{s} \text {. }
$$

Using $e_{s}$, and $e_{a}$ the vapor pressure deficit of the air $(\mathrm{kPa})$ was calculated as the difference;

$$
\mathrm{VPD}=e_{s}-e_{a} .
$$

\subsection{Leaf To Air VPD Calculation}

Leaf-to-air VPD was calculated for each temperature and relative humidity value reported on the data collection interval of 15 minutes across the irrigation treatments in both years. Calculations of leaf-to-air VPD were based on the difference in the water vapor pressure in the leaf (assuming 100\% humidity at the measured leaf temperature) minus the water vapor pressure in the air as described by Dai et al. 1992.

\subsection{ETc Calculation}

Crop evapotranspiration (ETc) was calculated using the CROPWAT system [15]. The ETc of the crop was calculated for a well-watered crop on a daily interval according to [15] where the daily crop evapotranspiration (ETc) is equal to the product of an $\mathrm{ET}_{\mathrm{o}}$ and a locally calibrated crop factor $\left(\mathrm{K}_{\mathrm{C}}\right) . \mathrm{ET}_{\mathrm{o}}$ was calculated using 
on-site weather station data and the Penman-Monteith equation [15].

\subsection{Dew Point Calculations}

Dew point temperatures $\left(T_{d}\right)$ were calculated by the Magnus-Tetens formula [14] [16] using measured air temperature $\left({ }^{\circ} \mathrm{C}\right)$ and relative humidity that were measured at $2 \mathrm{~m}$ above ground level on the edge of the field.

$$
T_{d}=b \gamma(T, R H) / a-\gamma(T, R H) \text { where } \gamma(T, R H)=(a T / b+T)+\ln (R H / 100)
$$

Constants are: $a=17.271, b=237.7^{\circ} \mathrm{C}$

\section{Results}

\subsection{Irrigation Treatments and Water Total for the Seasons}

Water received by the crop over the study interval is categorized as: rain, irrigation or total water (irrigation + rain). Thirteen daily irrigation amounts were targeted to provide a range of water from rainfed, with no in-season irrigation, up to full irrigation, intended to fully meet the estimated environmental water demand for the crop in each year. From the 13 target rates, 11 distinct irrigation rates were achieved (Table 1). In 2009, the eleven daily irrigation regimes achieved were: $0,0.5,1.0,2.0,3.0,3.5,4.0,4.5,5.0,5.5$, and $6.0 \mathrm{~mm} / \mathrm{day}$. In 2010, the eleven daily irrigation regimes achieved were: $0,0.5,1.0,1.5,2.0,2.5,3.0,3.5,4.0,4.5,5.0 \mathrm{~mm} /$ day. Nine of the irrigation regimes were common over the two years: $0,0.5,1.0,2.0,3.0,3.5,4.0,4.5,5.0 \mathrm{~mm} / \mathrm{day}$. The irrigation period was 76 days in 2009 and 41 days in 2010. The lower number of irrigation events in 2010 resulted from a delay in the initiation of irrigation due to early season rain events that ended prior to the canopy temperature monitoring period. Total rain between planting and harvest was $194 \mathrm{~mm}$ in 2009 and $309 \mathrm{~mm}$ in 2010. Rainfall patterns are evident in the $0 \mathrm{~mm}$ treatments in Figure 3(a) and Figure 3(b).

Based on the ETc values calculated for a well-watered crop, a range of water deficits was achieved in each year (Table 1). In 2009, the irrigation treatments received between $26 \%$ and $86 \%$ of seasonal ETc while in 2010 , total water ranged from $45 \%$ to $75 \%$ of the seasonal ETc. The crop in 2009 experienced a wider range of water deficits than the 2010 crop.

\subsection{Water/Yield Relationships}

The relationships between yield and seasonal water for 2009 and 2010 are shown in Figure 1 and Table 1. The

Table 1. Seasonal irrigation, total water (irrigation + rain), the fraction of seasonal ETc received by each irrigation treatment, and yield in 2009 and 2010. The designation of "na" indicates the target irrigation treatment that was not achieved due to irrigation system errors.

\begin{tabular}{|c|c|c|c|c|c|c|c|c|}
\hline \multirow{2}{*}{$\begin{array}{l}\text { Regime } \\
(\mathrm{mm})\end{array}$} & \multicolumn{4}{|c|}{ Crop Year 2009} & \multicolumn{4}{|c|}{ Crop Year 2010} \\
\hline & $\begin{array}{l}\text { Irrigation } \\
\text { (mm) }\end{array}$ & $\begin{array}{l}\text { Total Water } \\
\text { (mm) }\end{array}$ & Fraction ETc & $\begin{array}{l}\text { Yield } \\
\text { kg·ha }\end{array}$ & $\begin{array}{l}\text { Irrigation } \\
\quad(\mathrm{mm})\end{array}$ & $\begin{array}{l}\text { Total Water } \\
\text { (mm) }\end{array}$ & Fraction ETc & $\begin{array}{l}\text { Yield } \\
\mathrm{kg} \cdot \mathrm{ha}^{-1}\end{array}$ \\
\hline Rainfed & 0 & 194 & 0.26 & 439 & 0 & 309 & 0.45 & 611 \\
\hline 0.5 & 38 & 232 & 0.31 & 779 & 21 & 330 & 0.48 & 564 \\
\hline 1.0 & 76 & 270 & 0.36 & 1004 & 41 & 350 & 0.51 & 976 \\
\hline 1.5 & na & na & na & na & 62 & 371 & 0.54 & 877 \\
\hline 2.0 & 152 & 346 & 0.46 & 1439 & 82 & 391 & 0.57 & 1084 \\
\hline 2.5 & na & na & na & na & 103 & 412 & 0.60 & 1063 \\
\hline 3.0 & 228 & 422 & 0.56 & 2217 & 123 & 432 & 0.63 & 1055 \\
\hline 3.5 & 266 & 460 & 0.61 & 2157 & 144 & 453 & 0.66 & 1137 \\
\hline 4.0 & 304 & 498 & 0.66 & 2074 & 164 & 473 & 0.69 & 1842 \\
\hline 4.5 & 342 & 536 & 0.71 & 1970 & 185 & 494 & 0.72 & 1134 \\
\hline 5.0 & 380 & 574 & 0.76 & 2487 & 205 & 514 & 0.75 & 1698 \\
\hline 5.5 & 418 & 612 & 0.81 & 2257 & na & na & na & na \\
\hline 6.0 & 456 & 650 & 0.86 & 2620 & na & na & na & na \\
\hline
\end{tabular}




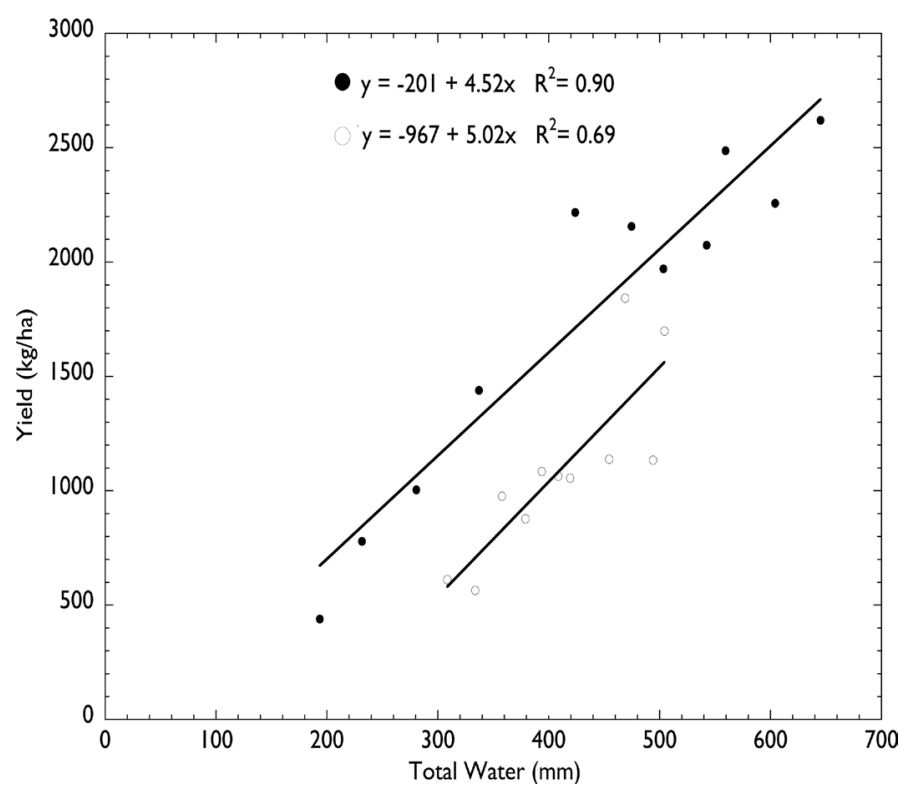

Figure 1. Cotton yield versus total water for 2009 and 2010 for cotton grown in Lubbock Texas. Total water is the sum of in-season rain and irrigation (subsurface drip).

seasonal total water across the irrigation treatments ranged from $194 \mathrm{~mm}$ to $650 \mathrm{~mm}$ in 2009 and from $309 \mathrm{~mm}$ to $514 \mathrm{~mm}$ in 2010 . The minimum yields are similar at $\sim 500 \mathrm{~kg} \cdot \mathrm{ha}^{-1}$ while the maximum yields are clearly different with $2620 \mathrm{~kg} \cdot \mathrm{ha}^{-1}$ in 2009 compared to $1850 \mathrm{~kg} \cdot \mathrm{ha}^{-1}$ in 2010.

The following sections will present a series of comparisons of environmental and plant data from the two years in an effort to explore the basis for the differences in yield versus water shown in Figure 1. Environmental factors include; air temperature, atmospheric humidity, and seasonal evapotranspiration, while the plant data in the analysis consists of seasonal canopy temperature measurements.

Three time periods were considered collection and analysis of data. The growing-season period covers the interval that begins at planting and ends at harvest, between DOY 135 and DOY 304 (169 days) in 2009 and DOY 139 and DOY 304 (165 days) in 2010. Water and yield measurements were made across this period. The canopy period, covering the period when the plant canopy was of sufficient size for canopy temperature to be monitored began 67 days after planting (DAP) in 2009 and ranged from DOY 202 to DOY 268 (66 days) and was similar in 2010, beginning at 66 DAP and ranging from DOY 205 to DOY 269 (64 days). Canopy temperature was monitored over this interval, and all analysis involving canopy temperature was made within this period. The irrigation period is the interval of daily irrigation and ranges from DOY 188 to DOY 265 (77 days) in 2009 and from DOY 215 to DOY 256 (41 days) in 2010.

Figure 2 shows patterns of air and dew point temperatures for the canopy period in 2009 (a) and 2010 (b). As a point of reference, the upper solid line indicates $40^{\circ} \mathrm{C}$, which has been suggested as an upper limit for cotton metabolic function [17] while the lower solid line indicates $28^{\circ} \mathrm{C}$, which has been previously proposed to represent a thermal optimum for cotton metabolism [18] [19]. The air temperatures were generally lower in 2009 than in 2010 with mean values of $25^{\circ} \mathrm{C}$ and $27^{\circ} \mathrm{C}$ respectively. During the period from DOY 212 to DOY 248 in 2010 , the maximum air temperatures routinely approached $40^{\circ} \mathrm{C}$, while the 2009 , the maximum temperatures were notably lower. The mean dew point was $16.5^{\circ} \mathrm{C}$ in 2009 and $15.9^{\circ} \mathrm{C}$ in 2010 . The differences in dew points (2009 dew point - 2010 dew point) are shown in Figure 2(c). The 2009 dew points were generally higher compared to 2010 from DOY 204 - 220 and higher in 2010 for DOY 260 - 268. However, while the mean dew point in 2009 was higher than in 2010, the values fluctuated around the 0 value indicating that seasonal dew points were similar for both years for much of the season. The pattern of dew point variation during the 2 years suggests that environmental demand, though different on average, was not consistently different over the season.

\subsection{Seasonal Environmental Demand (ETc)}

Crop water use is often characterized in terms of seasonal crop-evapotranspiration (ETc) that is predicted on the 

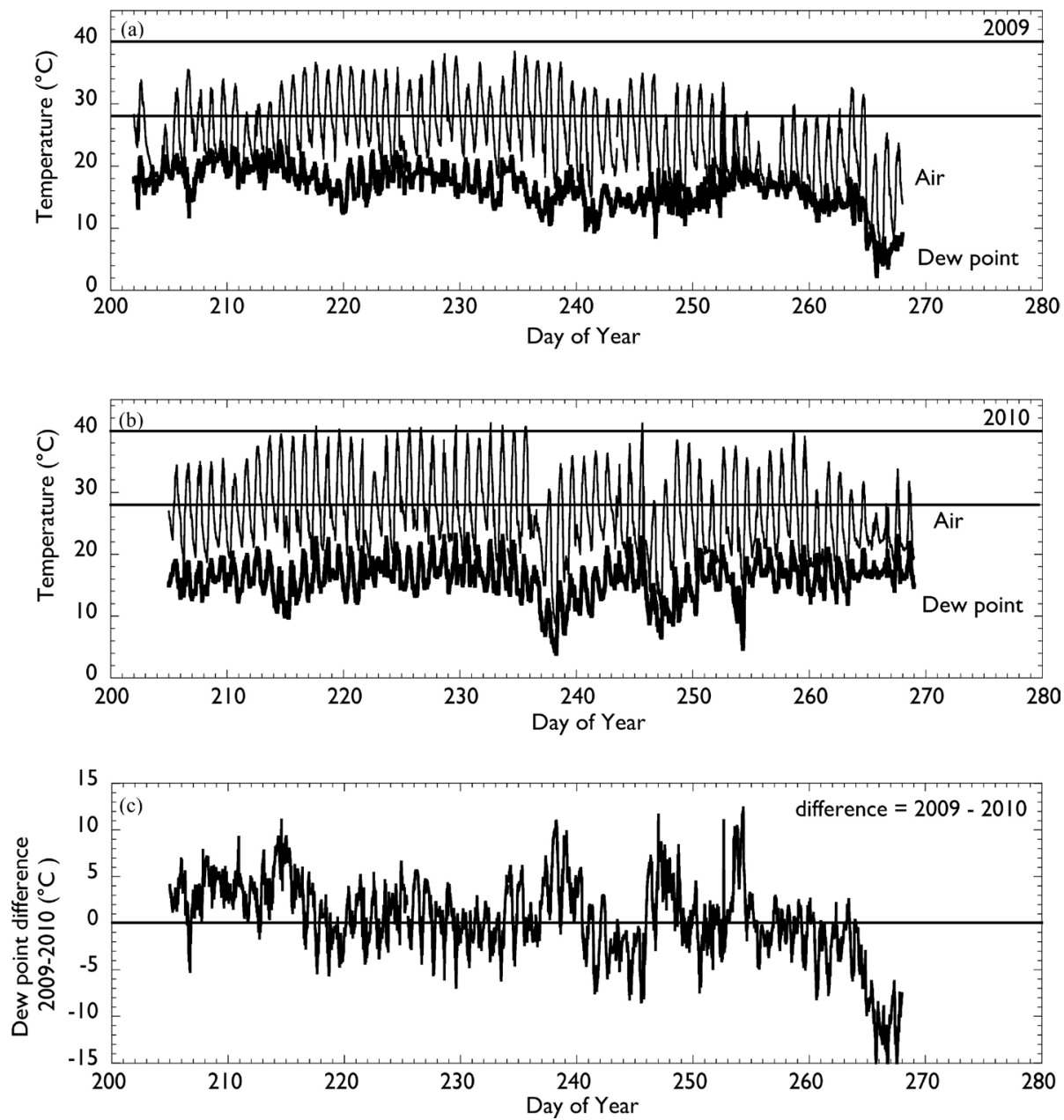

Figure 2. Seasonal patterns of air and dew point temperatures for 2009 (a) and 2010 (b) and dew point temperature difference (c) calculated from the 2009 and 2010 growing seasons in Lubbock, TX. The upper solid line in (a) and (b) indicates $40^{\circ} \mathrm{C}$ a proposed upper limit for cotton metabolic function while the lower solid line indicates $28^{\circ} \mathrm{C}$ which has been previously proposed to represent a thermal optimum for cotton metabolism. Dew point difference $=$ dew point $2009-$ dew point 2010 (c). Values > 0 indicate 2009 dew point higher than 2010. Negative values indicate 2010 dew point higher than 2009.

basis of radiation, air temperature and absolute humidity [14] [20]. The seasonal ETc for 2009 (754 mm) and 2010 (686 mm) is shown in Figure 3(a) and Figure 3(b). In perspective, during the 30-year period from1980 to 2010, ETc for Lubbock ranged from $650 \mathrm{~mm}$ to $850 \mathrm{~mm}$ [21]. The cumulative ETc between the two years differed by about 10\% with 2009 having the higher "environmental demand" of the two years (754 mm vs. 686 $\mathrm{mm})$. Thus while the 2009 growing season environmental demand was $68 \mathrm{~mm}$ higher than that in 2010, the seasons can be described as similar in terms of the accumulated ETc. Analysis of the derivative of ETc over time (data not shown) indicates that from DOY 134 to DOY 171 ETc accumulation was the same for both years. From DOY 171 to DOY 207, ETc accumulated faster in 2009 than in 2010 and from DOY 207 to DOY 269 ETc accumulated faster in 2010 than in 2009. Thus in comparison to 2010, ETc accumulation was greater in 2009 for a period of 36 days and lower for a period of 62 days. The seasonal patterns and magnitude of the differences are not indicative of drastically different environments and would be expected to only a marginally affect crop performance.

While the seasonal water deficits are useful for broad comparisons, the temporal patterns of the development and alleviation of water deficits over the course of the season can offer additional insight into stress. The patterns of cumulative crop evapotranspiration (ETc) and total water for the 2009 and 2010 growing seasons across selected irrigation treatments are shown in Figure 3(a) and Figure 3(b). Similar patterns are shown in Figure 3(c) 

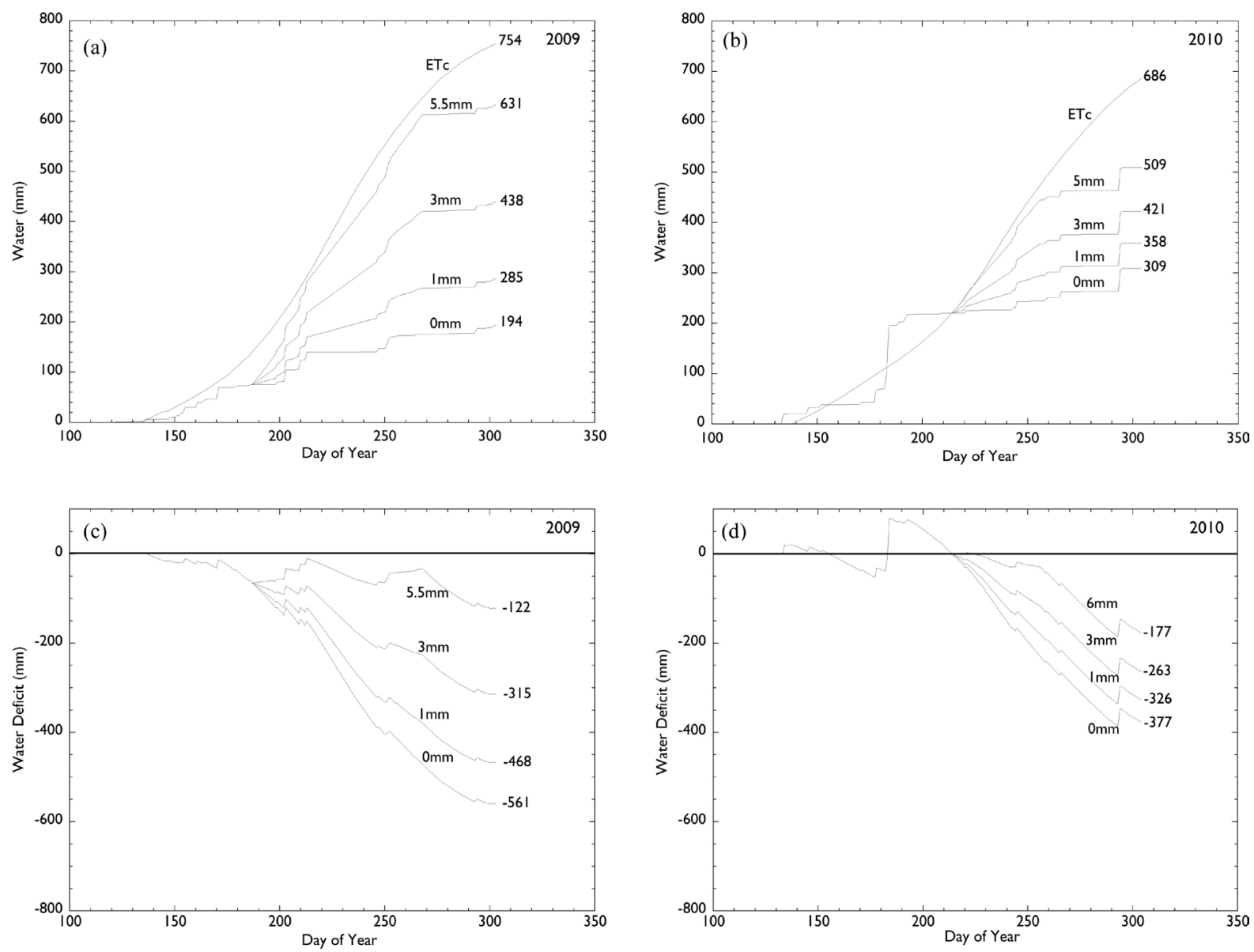

Figure 3. Crop evapotranspiration (ETc), total water and water balance for four irrigation treatments during the 2009 and 2010 growing seasons. ETc and total water in 2009 (a) and 2010 (b). Water balance in 2009 (c) and 2010 (d).

and Figure 3(d) as the pattern of water deficts in terms of total water (supply) versus the ETc (demand) for 2009 and 2010. The patterns of accumuation indicate that the relative differences between the two years were consistent.

\subsection{Seasonal Canopy Temperatures}

The canopy temperatures over the monitoring period in both years are shown in Figure 4. In each year, temperature data were collected from IRT sensors that were deployed in 11 irrigation treatments. Air (ambient) temperature, measured at $2 \mathrm{~m}$ above ground, is included as a reference in each figure. The shaded horizontal "bar" on the ambient temperature signature provides a $10^{\circ} \mathrm{C}$ temperature scale $\left(20^{\circ} \mathrm{C}\right.$ to $\left.30^{\circ} \mathrm{C}\right)$. The signatures show all data collected over each 24-hour day.

In Figure 5, the seasonal canopy temperatures have been filtered to exclude values below $27^{\circ} \mathrm{C}$ in order to indicate temperatures that are most influenced by water status. The $27^{\circ} \mathrm{C}$ filter value was chosen to indicate the transition from optimal to non-optimal temperatures that is reported to inidcate the development of water deficits in cotton [11] [18]. Since the canopy temperatures have been filtered with respect to a stress indicator, it is proposed that such figures represent "stress signatures". The "gaps" in the signatures indicate temperatures below $27^{\circ} \mathrm{C}$ as opposed to missing data.

In the 2009 stress signatures (Figure 5(a)), there is a general pattern of decreasing stress with increasing irrigation. Canopy temperatures were elevated in the 4mm treatment during the interval from DOY 210 to DOY 225, after which they returned to values more typical of the irrigation treatment. This pattern indicates higher transpiration relative to the $4 \mathrm{~mm}$ in all irrigation levels. There is a mid-season period of elevated canopy temperatures between DOY 232 and DOY 240.

In 2010, the stress signatures (Figure 5(b)) were responsive to irrigation treatments with increasing thermal 
stress evident across irrigation treatments. The signature of the $4 \mathrm{~mm}$ treatment suggested less stress across the season than would be expected relative to the $4.5 \mathrm{~mm}$ and $5 \mathrm{~mm}$ signatures. In a similar manner, the $2 \mathrm{~mm}$ treatment appears cooler than the $2.5 \mathrm{~mm}, 3 \mathrm{~mm}$ or $3.5 \mathrm{~mm}$ treatments. Perhaps the most apparent characteristic of the 2010 stress signatures is the general elevation of temperatures and stress relative to the 2009 patterns.

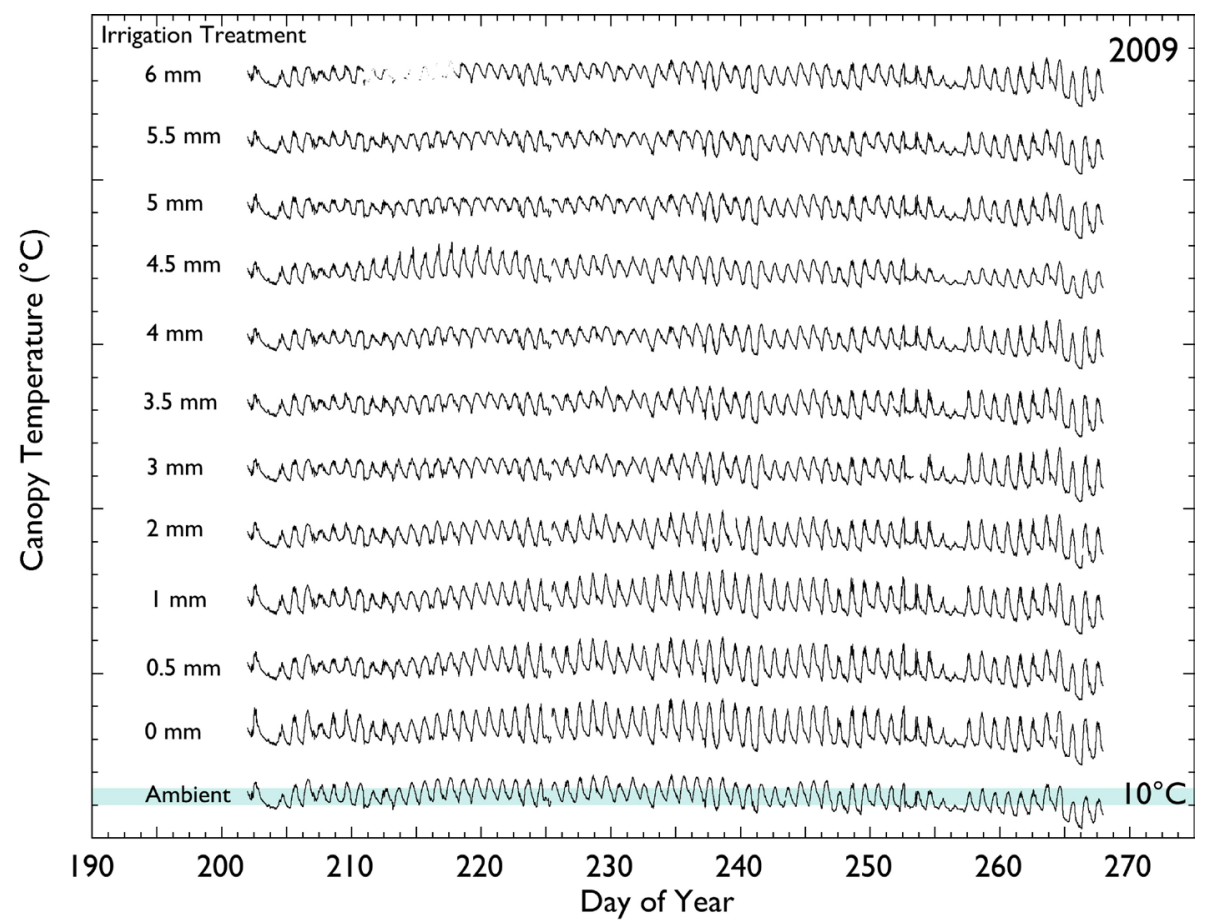

(a)

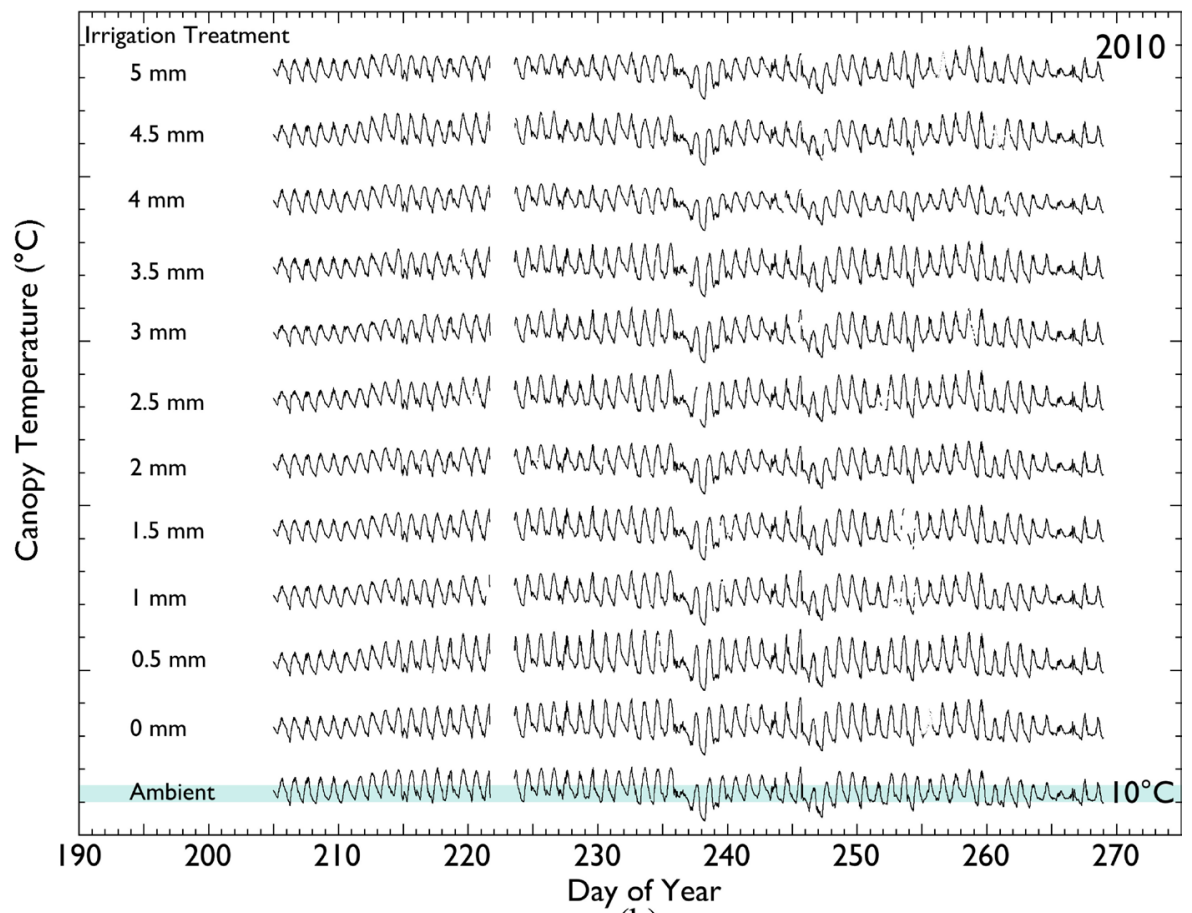

(b)

Figure 4. Canopy temperature signatures from the 2009 (a) and 2010 (b) growing season across 11 irrigation treatments (text on left of figure). The colored bar represents a $10^{\circ} \mathrm{C}$ interval from $20^{\circ} \mathrm{C}$ to $30^{\circ} \mathrm{C}$. 


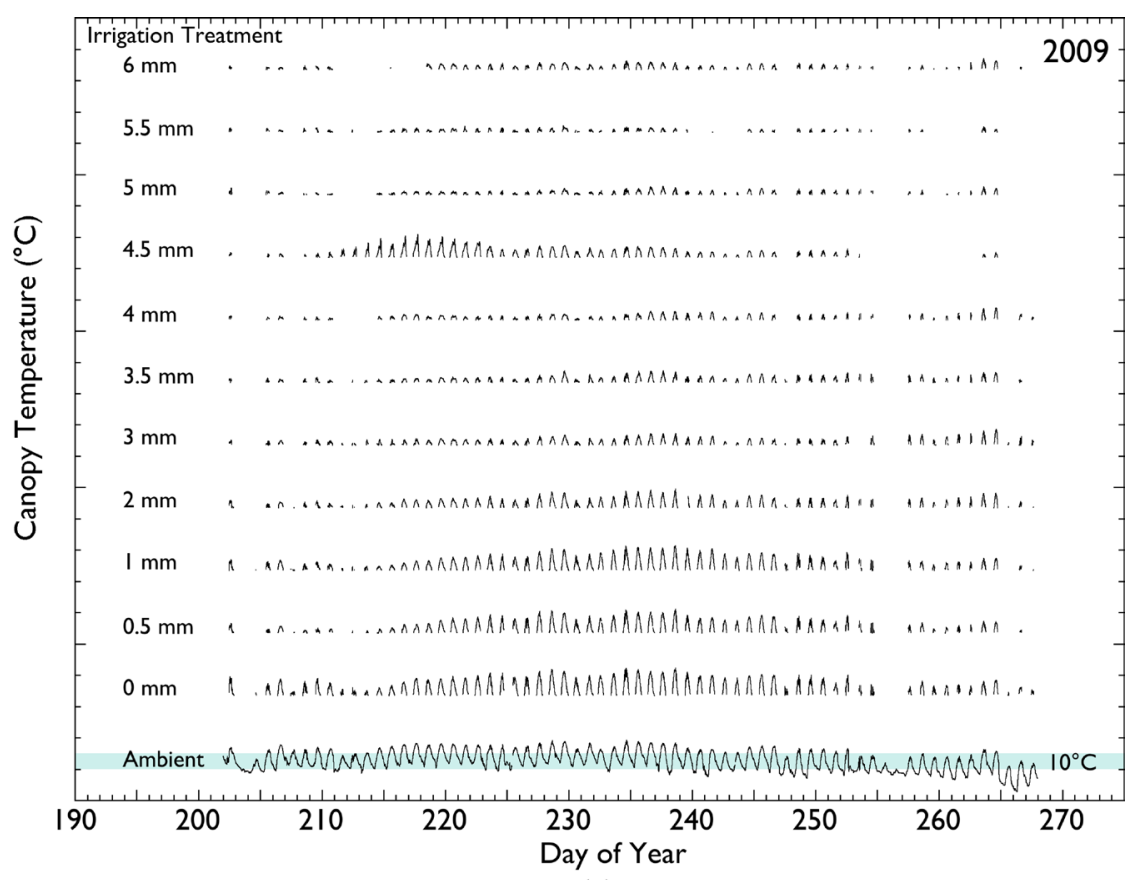

(a)

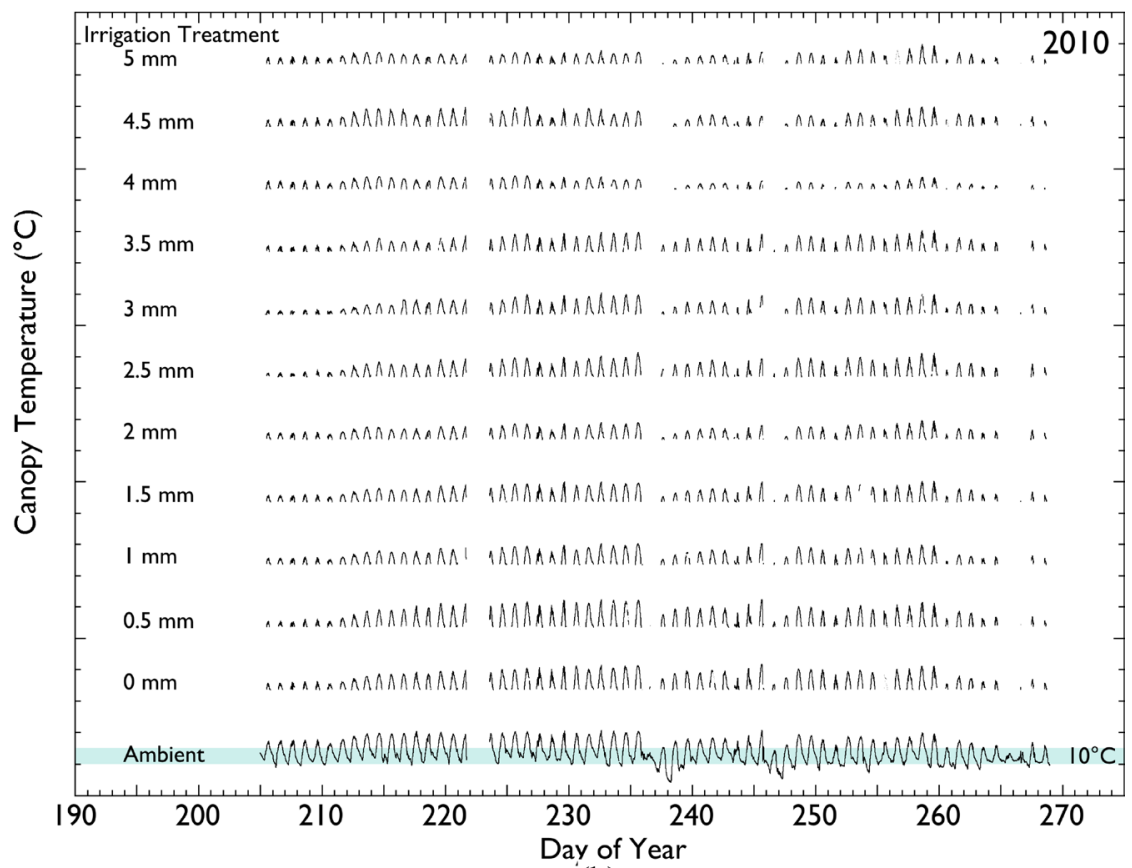

(b)

Figure 5. Seasonal canopy temperature stress signatures from the 2009 (a) and 2010 (b) growing season across 11 irrigation treatments (text on left of figure). Canopy temperatures below $27^{\circ} \mathrm{C}$ are removed. The colored bar represents a $10^{\circ} \mathrm{C}$ interval from $20^{\circ} \mathrm{C}$ to $30^{\circ} \mathrm{C}$.

\subsection{Canopy Temperature and Yield Relationships}

Figure 1 presented the relationship between yield and total water for the total of 22 irrigation regimes over the two years of the study. In each year, yield was correlated with total water and between the years the slopes of the lines were similar while the intercepts were different. The patterns of canopy temperature in various irrigation regimes over the two years of the study varied in a manner that indicates that the canopy temperature was 
sensitive to plant water status. Given that seasonal canopy temperature measurements are related to plant water status and water use the question arises as to the extent to which seasonal canopy temperature is related to the yield variation.

Figure 6 shows the relationship between the cumulative daytime leaf-to-air VPD and yield for 2009 and 2010. The figure characterizes the relationship between yield and the environment in the context of a plant-based indicator of evaporative demand in terms of the gradient for water movement from the leaf to the surrounding air. The cumulative leaf-to-air VPD could thus be an indicator of cumulative water use and yield. The relationship between yield and cumulative leaf-to-air VPD is similar to that between yield and total water shown in Figure 1, that is the regression lines are similar in slope with different intercepts.

Yield was plotted as a function of the average canopy temperature for each of the irrigation treatments in the two years (Figure 7(a)). Two notable characteristics of the relationship are that the regression coefficients are both $>0.9$, and the slopes and intercepts are similar for the two years. Thus, the two years that were previously described by two lines, in terms of yield vs total water and yield vs cumulative daytime leaf-to-air VPD, merge into a single line with respect to yield and average canopy temperature.

Since the relationship between canopy temperature and plant water use is most apparent during daylight hours, the relationship between average canopy temperature during the daytime (8:00 am to 8:00 pm) and yield was also examined (Figure 7(b)).The daytime filtering of canopy temperature improves the agreement between the water and yield relationships between the years. The relationship across the two years of the study suggests that average daytime canopy temperature may prove to be a useful indicator of crop water use on a seasonal basis.

Figure 8 shows the relationship between cumulative daytime canopy temperature and yield for 2009 and 2010. The relationship between cumulative daytime temperature and yield in 2009 and 2010 is well-described by a single regression line with the fit of the regression slightly increased relative to the previous expressions.

Yield in this study was found to be correlated, to varying degrees, with seasonal total water and four indicators of crop water use that were based on the continuously monitored canopy temperatures in the irrigation regimes over the two seasons of the study. Table 2 compares the results of linear regressions of yield and water and the four canopy temperature based indicators.

\section{Discussion}

\subsection{Total Water and Yield}

In this study, a total of 22 irrigation treatments were implemented in cotton over the 2009 and 2010 growing

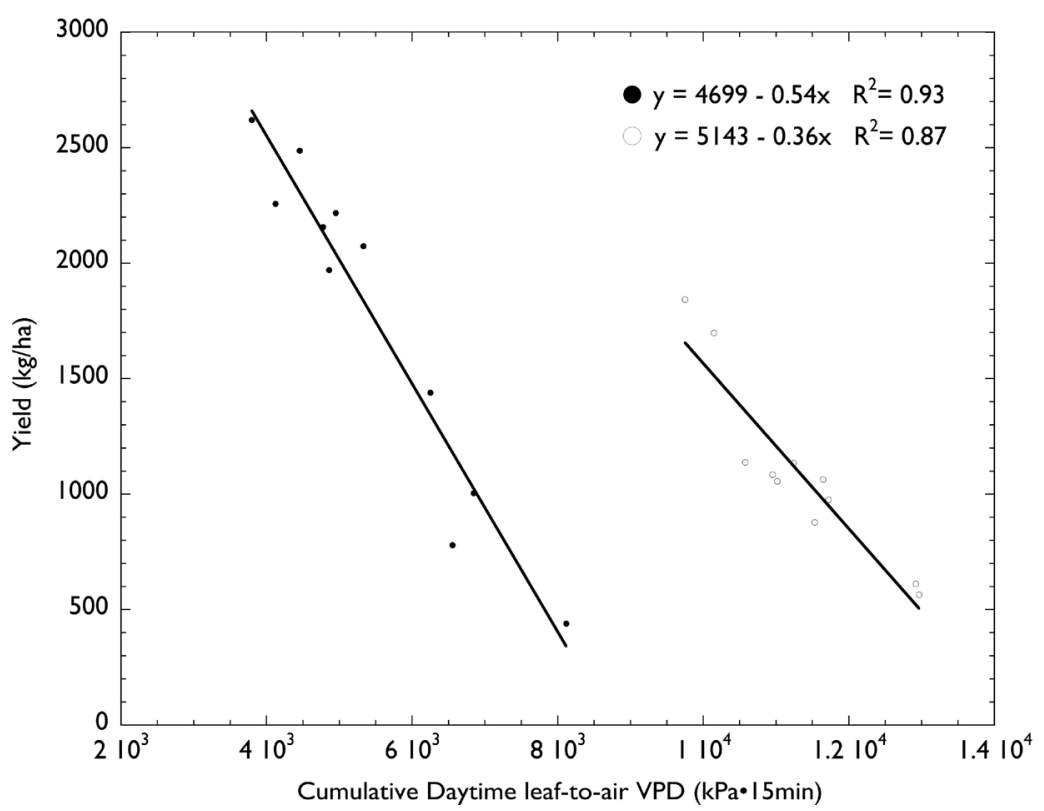

Figure 6. Cumulative leaf-to-air vapor pressure deficit and yield for 2009 and 2010. Daytime leaf-to-air VPD includes values between 8:00 am and 8:00 pm. 


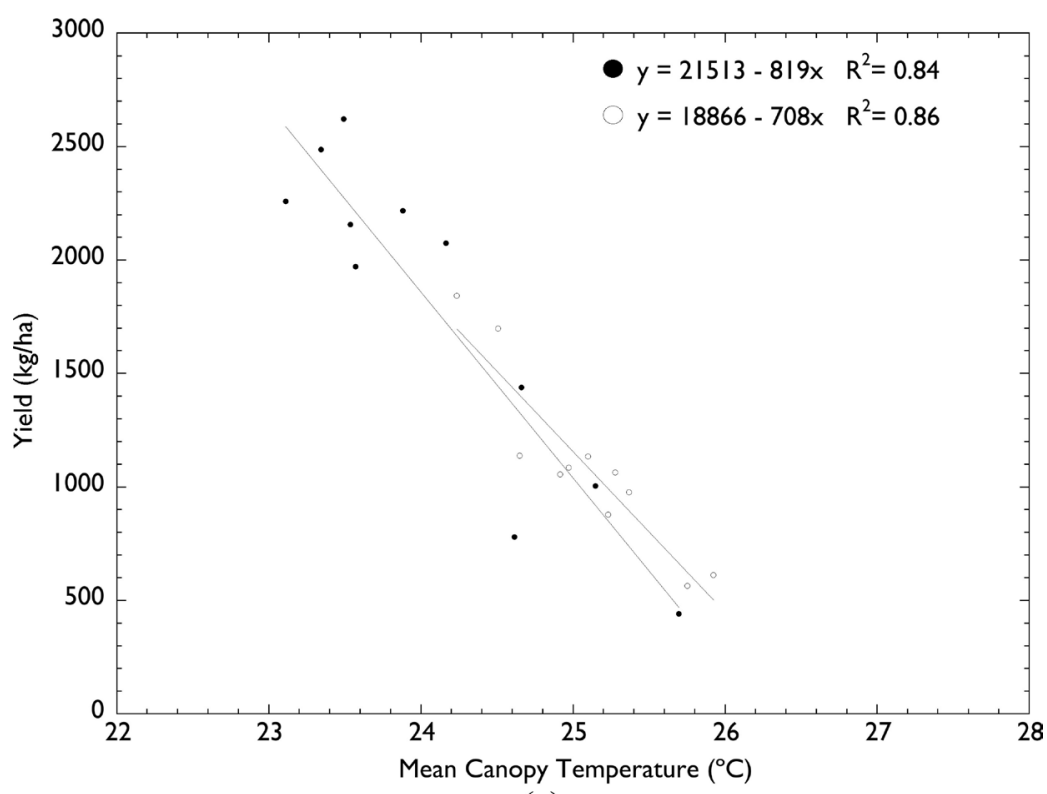

(a)

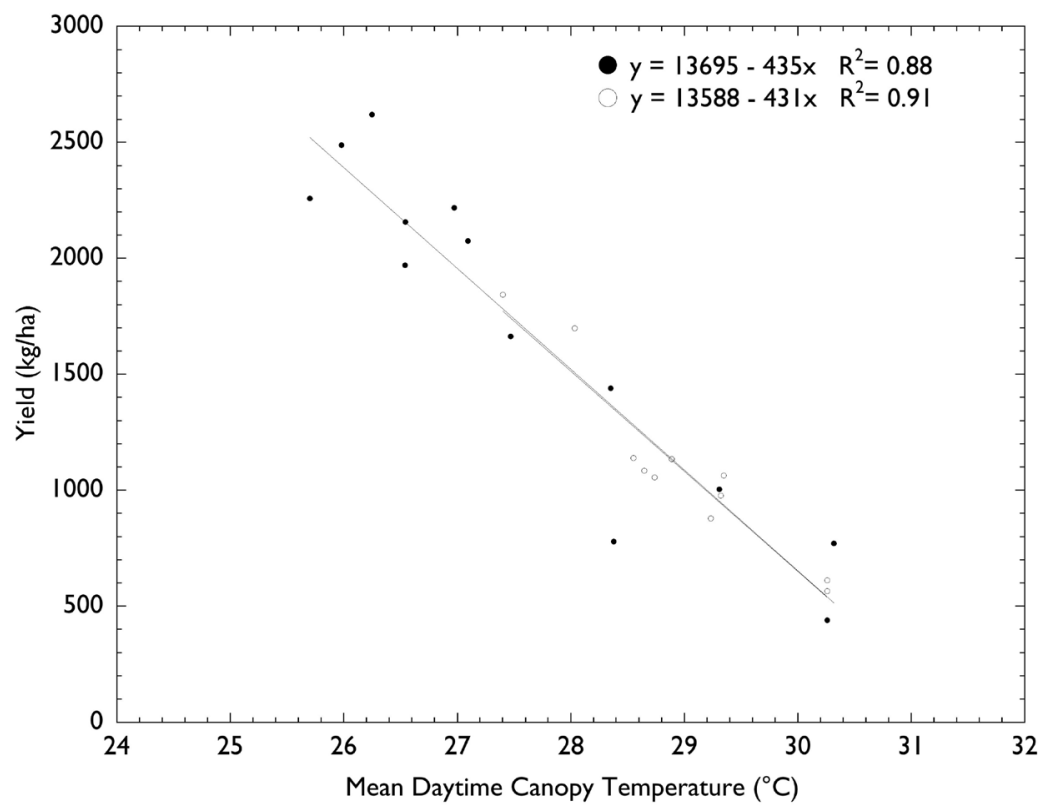

(b)

Figure 7. Average canopy temperature and yield for 2009 and 2010. Mean canopy temperature (a) and mean daytime canopy temperature (b). Daytime canopy temperature includes temperature values between 8:00 am and 8:00 pm.

seasons in Lubbock, Texas. Yield varied in proportion to the total water in each season (Figure 1) with the relationships described by a linear fit with similar slopes and different intercepts. The similar slopes indicate that the fiber yield per unit of water received was similar for both years, but the minimum yield (the y-intercept) was different suggesting a difference in yield potential in the two years.

The environmental conditions differed between the two seasons in terms of air temperatures and humidity (Figure 2). There was more in-season rainfall in 2010 than in 2009 and higher in-season ETc for 2009 (Figure 3). The seasonal patterns and magnitude of the differences in measured and calculated environmental demand parameters are not indicative of drastically different environments and would be expected to have only a marginal effect on crop performance. Additionally the seasons are similar in terms of accumulated water-deficits and the timing of water-deficit stress (Figure 3). 


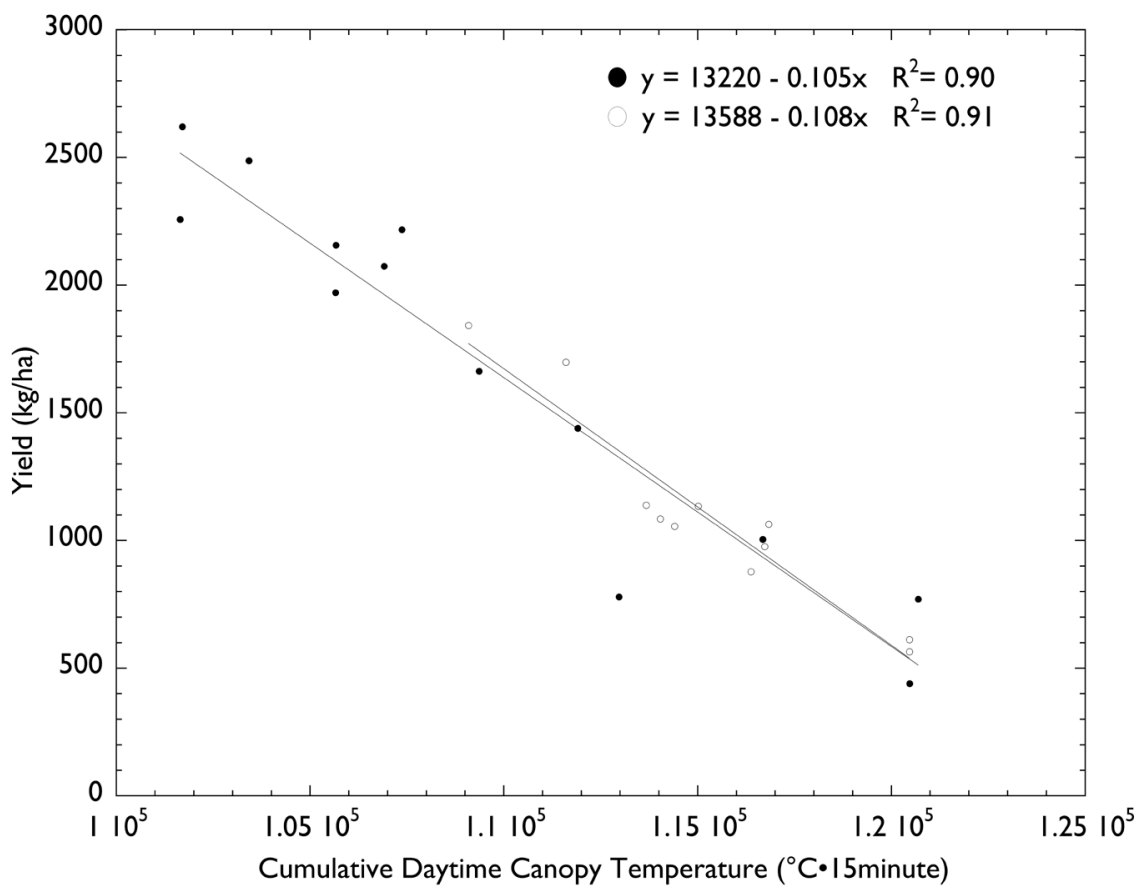

Figure 8. Cumulative daytime canopy temperature and yield for 2009 and 2010. Daytime canopy temperature includes temperature values between 8:00 am and 8:00 pm.

Table 2. Comparison of linear regressions of cotton yield versus five indicators of plant water use for eleven irrigation treatments in 2009 and 2010 in Lubbock, TX. Total Wate $\mathrm{r}=$ rainfall + irrigation, $\mathrm{VPD}_{\mathrm{L}}=$ cumulative leaf-to-air vapor pressure deficit, $T_{c}=$ mean canopy temperature, Daytime $T_{c}=$ mean daytime canopy temperature $(8: 00 \mathrm{am}$ to 8:00 pm), Cumulative Daytime $T_{c}=$ cumulative daytime canopy temperature (8:00 am to 8:00 pm).

\begin{tabular}{ccccccccc}
\hline \multirow{2}{*}{ Indicator } & \multicolumn{2}{c}{ Slope } & \multicolumn{2}{c}{ Intercept } & \multicolumn{2}{c}{$\mathrm{R}$} & \multicolumn{2}{c}{ Figure } \\
\cline { 2 - 8 } & 2009 & 2010 & 2009 & 2010 & 2009 & 2010 & \\
\hline Total Water & 4.41 & 5.02 & 131 & 967 & 0.91 & 0.7 & 1 \\
VPD $_{\mathrm{L}}$ & -0.54 & -0.36 & 4699 & 5143 & 0.96 & 0.94 & 6 \\
$\mathrm{~T}_{\mathrm{c}}$ & -818 & -708 & 21,513 & 18,866 & 0.92 & 0.93 & $7 \mathrm{a}$ & $7 \mathrm{~b}$ \\
Daytime $\mathrm{T}_{\mathrm{c}}$ & -435 & -431 & 13,695 & 13,588 & 0.94 & 0.95 & 8 \\
Cumulative Daytime $\mathrm{T}_{\mathrm{c}}$ & -0.105 & -0.108 & 13,220 & 13,588 & 0.95 & 0.95 & 8 \\
\hline
\end{tabular}

While the temporal patterns of the development and alleviation of water deficits over the course of the season can offer additional insight into stress, the patterns of stress accumulation (Figure 3(c) and Figure 3(d)) indicate that the relative differences between the two years were consistent. The balance between ETc and total water over the season is shown in Figure 3(c) and Figure 3(d) where the "0" value indicates when the total water matched estimated environmental water demand with positive values indicating water in excess of estimated environmental demand and negative values indicating water deficit. The slope of the line indicates the trend in the balance. A negative slope in the positive range indicates that water was declining relative to demand at a moment in time even though the net balance was still positive. A slope of 0 indicates that supply and demand are balanced regardless of whether the net balance is positive or negative.

In 2009, water deficits continually accrued over the season with the net balance never becoming positive (Figure 3(c)). Periodic rain events occasionally produced positive slopes resulting in water supply exceeding crop demand. Approximately half of the seasonal deficit in the $5.5 \mathrm{~mm}$ irrigation treatment developed before irrigation was initiated with the water balance largely stable during the irrigation period. The other irrigation treatments were in a state of decline even after the onset of irrigation with only minor deviations from the trend in response to rain events. 
In 2010, rainfall in early July initially caused the water balance to become positive with the water balance generally declining over the remainder of the season (Figure 3(d)). The slope of the $5 \mathrm{~mm}$ treatment was shallow (neutral) between DOY 210 and DOY 260 indicating that water lost was balanced by water added over this period.

Canopy temperature has been previously proposed to be an indicator of plant water use that can be used to detect differences in water deficits [13] [19] [22]. Canopy temperature for the irrigation regimes in both years is shown in (Figure 4). Air temperature is included in each figure with the shaded horizontal "bar" on the air temperature indicating a $10^{\circ} \mathrm{C}$ temperature scale. This type of data graph is based on the Sparkline approach proposed by E. Tufte [23]. The term "temperature signature" is proposed for this presentation of canopy temperature which provides an overview of both the magnitude and pattern of variation and the continuity of the temperature monitoring (gaps in the figures indicate missing data).

Since the temperature signatures include night and day temperatures, they are not particularly informative with respect to visualizing the relationship between canopy temperature and crop water status. Differences in plant water status are most evident during daylight hours and thus roughly $50 \%$ of the temperatures that appear in the canopy temperature signatures contain very little information on plant water status. Figure 5 shows the seasonal canopy temperatures that have been filtered to exclude values below $27^{\circ} \mathrm{C}$, a temperature that indicates the development of water deficits and metabolic stresses in cotton [11] [24]. Such a filter essentially eliminated night-time canopy temperatures. We propose the term stress signatures to describe canopy temperatures have been filtered with respect to a stress indicator. Stress signatures may have value for a "forest vs. trees" analysis of the canopy temperatures with the height and width of the peaks indicating the magnitude of the stress and its pattern over the season.

Seasonal stress signatures facilitate the visual inspection of the seasonal data to identify trends and differences among treatments. In 2009 (Figure 5(a)), a general pattern of decreasing stress with increasing irrigation was evident. The $5.5 \mathrm{~mm}$ treatment appears to have experienced less stress than the $6 \mathrm{~mm}$ treatment suggesting that the $5.5 \mathrm{~mm}$ canopy was transpiring at a higher rate than the $6 \mathrm{~mm}$ treatment. The 2010 stress signatures (Figure 5(b)) generally reflect the irrigation regimes with increasing thermal stress evident among the irrigation treatments. The signature of the $4 \mathrm{~mm}$ treatment suggests less stress across the season than would be expected relative to the $4.5 \mathrm{~mm}$ and $5 \mathrm{~mm}$ signatures.

Comparison of the 2009 and 2010 stress signatures indicates that the 2009 season had a wider range of canopy temperatures among the irrigation regimes which is in agreement with the wider range of water deficits (Figure 3 and Table 1). When compared to the 2009 stress signatures, it is apparent that the canopy temperatures in 2010 were higher across all the irrigation levels for the entire measurement period. Of the 2010 stress signatures, only the $4 \mathrm{~mm}$ treatment indicates temperatures that were near the $28^{\circ} \mathrm{C}$ optimum which is in marked contrast to the 2009 results that showed several irrigation treatments with canopy temperatures in the $28^{\circ} \mathrm{C}$ range ( $5 \mathrm{~mm}, 5.5 \mathrm{~mm}$, and $6 \mathrm{~mm}$ ).

\subsection{Canopy Temperature-Based Indicators of Crop Water Use}

For plant canopies at a single location, at a moment in time, when air temperature, humidity and radiation are all fundamentally similar, the relationship between transpiration and canopy temperature is well defined. Seasonal canopy temperature may provide a near-continuous surrogate for transpiration of the crop and comparisons of canopy temperatures across irrigation regimes and between seasons indicate both water supply and environmental demands.

Over the course of this study a set of approximately 250,000 canopy temperature measurements was collected to investigate the extent to which seasonal canopy temperature measurements might be used to indicate differences in plant water use. The canopy temperature data set was used to investigate the relationship between canopy temperature and yield in terms of; cumulative leaf-to-air VPD, mean canopy temperature, and cumulative canopy temperature.

The atmospheric vapor pressure deficit (VPD) describes the gradient for water movement from the plant to the air. Higher VPD is generally assoicated with greater water use [25]-[28]. When the relationship between air and canopy temperature is stable and/or predictable (e.g. uniform irrigation within a single season), the atmospheric VPD is often a useful means of assessing transpiration on a seasonal basis. When canopy temperatures are known, the leaf-to-air VPD, also a measure of potential transpiration can be calculated. Leaf-to-air VPD values that 
incorporate both the dryness of the environment (humidity) and a measure of the water status of the plant (canopy temperature) may represent a useful measure of seasonal water use that could explain yield variation. Cumulative seasonal leaf-to-air VPD was related to yield across irrigation treatments in the two years of the study (Figure 6) in a manner similar to the total water (Figure 1).

Given that canopy temperature varied in accord with the irrigation treatments in both years of the study (Figure 5), the utility of canopy temperature as a surrogate for plant water use in yield and water relationships was investigated. The seasonal average canopy temperature, perhaps the most simple analysis possible, largely accounted for yield variation across irrigation regimes between the two seasons with a single function (Figure 7(a) and Table 2). Limiting the mean canopy temperature analysis to daytime values improved the fit of the yield relationships (Figure $7(\mathbf{b})$ and Table 2) underscoring that canopy temperature differences are most pronounced when the environmental demand is greatest.

The cumulative daytime canopy temperature over the season was closely linked to yield across irrigation treatments and seasons (Figure 8 and Table 2) with a single line accounting for a large portion of the yield variation. Since yield and water use are incremental and cumulative, it is reasonable for cumulative canopy temperature to be related to yield. Cumulative daytime canopy temperature was arguably the best indicator of yield variation in the study and may provide a useful indicator of crop water status and water use.

Near-continuous seasonal canopy temperature has at least four advantages as an indicator of crop water status and use: 1) it is a direct measure of the plant 2) it can be mechanistically associated with transpiration and thermal effects on metabolism 3) it is continuous and can be accumulated on seasonal timeframes and 4) it is relatively easy to measure in both research and production settings.

For a single location and within a given season, the relationship between canopy temperature and crop water use is rather straightforward and with the seasonal measurements at 15-minute intervals there are several thousand measurements available for analysis. This near-continuous measure of water use lends strength to average and cumulative canopy temperature analyses. Filtering to include only daytime temperatures strengthens the yield relationships by accentuating those time periods when canopy temperature might be most affected by plant water status.

Inclusion of canopy temperature monitoring in studies of the relationships between water and yield may prove worthwhile as a routine measurement. In such instances a general rule for canopy temperature monitoring might be stated as "come early and stay late". Ideally, sensors should be installed at planting and removed at the end of the growing season.

\section{Conclusions}

At this point, it is suggested that canopy temperature, measured on a fine time interval across a growing season may provide additional insight into water status and water use of the crop. Four canopy temperature based indicators of plant water use were compared in terms of their ability to account for yield variation. The leaf-toair VPD [25] [29], an indicator that combined environmental demand (humidity) and plant water status (canopy temperature), accounted for yield variation among irrigation treatments within a growing season but not between seasons. The three indicators that were based solely on canopy temperature; mean canopy temperature, mean daytime canopy temperature, and cumulative daytime canopy temperature, produced a single linear relationship that accounted for yield variation across irrigation regimes in both years.

While canopy temperature measurements have been used for decades as a tool for monitoring the water status of crops, recent advances in in-field data result in commercially available systems that are well-suited to agricultural use. Near-continuous canopy temperature collected on a seasonal timescale will provide insight into crop water use that is difficult to obtain by other methods. Currently, canopy temperature is perhaps the only plant parameter that can be monitored near-continuously on seasonal timescales in an automated manner that is compatable with both research and production settings.

\section{References}

[1] Smith, D.M. and Allen, S.J. (1996) Measurement of Sap Fow in Plant Stems. Journal of Experimental Botany, 47, 1833-1844. http://dx.doi.org/10.1093/jxb/47.12.1833

[2] Steppe, K.D., De Pauw, J.W. and Lemeur, R. (2008) A Step towards New Irrigation Scheduling Strategies Using PlantBased Measurements and Mathematical Modelling. Irrigation Science, 26, 505-517. 
http://dx.doi.org/10.1007/s00271-008-0111-6

[3] Lee, K.M., Driever, S.M., Heuvelink, E. and Rüger, S. (2012) Evaluation of Diel Patterns of Relative Changes in Cell Turgor of Tomato Plants Using Leaf Patch Clamp Pressure Probes. Physiologia Plantarum, 146, 439-447. http://dx.doi.org/10.1111/j.1399-3054.2012.01637.x

[4] Hunsaker, D.J., Barnes, E.M., Clark, T.R., Fitzgerald, G.J. and Pinter, P.J. (2005) Cotton Irrigation Scheduling Using Remotely Sensed and FAO-56 Basal Crop Coefficients. Transactions of the American Society of Agricultural Engineers, 48, 1395-1407. http://dx.doi.org/10.13031/2013.19197

[5] Evett, S.R. and Parkin, G.W. (2005) Advances in Soil Water Content Sensing the Continuing Maturation of Technology and Theory. Vadose Zone Journal, 4, 986-991. http://dx.doi.org/10.2136/vzj2005.0099

[6] Leib, B.G., Jabro, J.D. and Matthews, G.R. (2003) Field Evaluation and Performance Comparison of Soil Moisture Sensors. Soil Science, 168, 396-408. http://dx.doi.org/10.1097/01.ss.0000075285.87447.86

[7] Evett, S.R., Schwartz, R.C., Tolk, J.A. and Howell, T.A. (2009) Soil Profile Water Content Determination: Spatiotemporal Variability of Electromagnetic and Neutron Probe Sensors in Access Tubes. Vadose Zone Journal, 8, $926-941$. http://dx.doi.org/10.2136/vzj2005.0099

[8] Jackson, R.D., Idso, S.B., Reginato, R.J. and Pinter, P.J. (1981) Canopy Temperature as a Crop Water Stress Indicator. Water Resources Research, 17, 1133-1138.http://dx.doi.org/10.1029/WR017i004p01133

[9] Idso, S.B., Jackson, R.D., Pinter, P.J., Reginato, R.J. and Hatfield, J.L. (1981) Normalizing the Stress Degree Day Parameter for Environmental Variability. Agricultural Meteorology, 24, 45-55. http://dx.doi.org/10.1016/0002-1571(81)90032-7

[10] Upchurch, D.R., Wanjura, D.F., Burke, J.J. and Mahan, J.R. (1996) Biologically-Identified Optimal Temperature Interactive Console (BIOTIC) for Managing Irrigation. US Patent 5, 539.637.

[11] Wanjura, D.F., Upchurch, D.R. and Mahan, J.R. (2006) Behavior of Temperature-Based Water Stress Indicators in BIOTIC-Controlled Irrigation. Irrigation Science, 24, 223-232. http://dx.doi.org/10.1007/s00271-005-0021-9

[12] Mahan, J.R. and Yeater, K.M. (2008) Agricultural Applications of a Low-Cost Infrared Thermometer. Computers and Electronics in Agriculture, 64, 262-267. http://dx.doi.org/10.1016/j.compag.2008.05.017

[13] Mahan, J.R., Young, A.W. and Payton, P. (2012) Deficit Irrigation in a Production Setting: Canopy Temperature as an Adjunct to ET Estimates. Irrigation Science, 30, 127-137. http://dx.doi.org/10.1007/s00271-011-0269-1

[14] Murray, F.W. (1967) On the Computation of Saturation Vapor Pressure. Journal of Applied Meteorology, 6, $203-204$. http://dx.doi.org/10.1175/1520-0450(1967)006<0203:OTCOSV>2.0.CO;2

[15] Allen, R.G., Pereira, L.S., Raes, D. and Smith, M. (1998) Crop Evapotranspiration. FAO Irrigation and Drainage Paper 56. Food and Agricultural Organization of the UN, Rome.

[16] Barenbrug, A.W.T. (1974) Psychrometry and Psychrometric Charts. 3rd Edition, Cape and Transvaal Printers Ltd., Cape Town.

[17] Perry, S.W., Krieg, D.R. and Hutmacher, R.B. (1983) Photosynthetic Rate Control in Cotton: Photorespiration. Plant Physiology, 73, 662-665. http://dx.doi.org/10.1104/pp.73.3.662

[18] Mahan, J.R. and Upchurch, D.R. (1988) Maintenance of Constant Leaf Temperature By Plants. 1. Hypothesis of Limited Homeothermy. Environmental and Experimental Botany, 28, 351-357. http://dx.doi.org/10.1016/0098-8472(88)90059-7

[19] Wanjura, D.F. and Mahan, J.R. (1994) Thermal Environment of Cotton Irrigated Using Canopy Temperature. Irrigation Science, 14, 199-205. http://dx.doi.org/10.1007/BF00190191

[20] Smith, M., Allen, R.G., Monteith, J.L., Pereira, L.S., Perrier, A. and Pruitt, W.O. (1991) Report on the Expert Consultation on Revision of FAO Guidelines for Crop Water Requirements, Land and Water Dev. Division, FAO, Rome. http://www.fao.org/WAICENT/FaoInfo/Agricult/agl/aglw/webpub/REVPUB.htm

[21] Mauget, S.A. and Leiker, G. (2010) The Ogallala Agro-Climate Tool. Computers and Electronics in Agriculture, 74, 155-162. http://dx.doi.org/10.1016/j.compag.2010.08.002

[22] Jackson, R.D. (1981) Soil Moisture Inferences from Thermal Infrared Measurements of Vegetation Temperatures. International Geosience and Remote Sensing Symposium, I, 364-374.

[23] Tufte, E.R. (2006) Beautiful Evidence. Graphics Press LLC, Cheshire.

[24] Burke, J.J., Mahan, J.R. and Hatfield, J.L. (1988) Crop-Specific Thermal Kinetic Windows in Relation to Wheat and Cotton Biomass Production. Agronomy Journal, 80, 553-556. http://dx.doi.org/10.2134/agronj1988.00021962008000040001x

[25] Dai, Z., Edwards, G.E. and Ku, M.S. (1992) Control of Photosynthesis and Stomatal Conductance in Ricinus communis L. (Castor Bean) by Leaf to Air Vapor Pressure Deficit. Plant Physiology, 99, 1426-1434. 
http://dx.doi.org/10.1104/pp.99.4.1426

[26] Tibbitts, T.W. (1979) Humidity and Plants. BioScience, 29, 358-363. http://dx.doi.org/10.2307/1307692

[27] Bunce, J.A. (1997) Does Transpiration Control Stomatal Responses to Water Vapour Pressure Deficit? Plant Cell and Environment, 20, 131-135. http://dx.doi.org/10.1046/j.1365-3040.1997.d01-3.x

[28] Angus, J.F. and van Herwaarden, A.F. (2001) Increasing Water Use and Water Use Efficiency in Dryland Wheat. Agronomy Journal, 93, 290-298. http://dx.doi.org/10.2134/agronj2001.932290x

[29] Baker, J.T., Gitz, D.C., Payton, P., Wanjura, D.F. and Upchurch, D.R. (2007) Using Leaf Gas Exchange to Quantify Drought in Cotton Irrigated Based on Canopy Temperature Measurements. Agronomy Journal, 99, 637-644. http://dx.doi.org/10.2134/agronj2006.0062 